\title{
Neuroprotective and Antioxidant Effect of Ginkgo biloba Extract Against AD and Other Neurological Disorders
}

\author{
Sandeep Kumar Singh ${ }^{1} \cdot$ Saurabh Srivastav ${ }^{2} \cdot$ Rudolph J. Castellani $^{3} \cdot$ Germán Plascencia-Villa $^{4} \cdot$ George Perry $^{4}$ (i)
}

Published online: 2 August 2019

(C) The American Society for Experimental NeuroTherapeutics, Inc. 2019

\begin{abstract}
Alzheimer's disease (AD) is the most common progressive human neurodegenerative disorder affecting elderly population worldwide. Hence, prevention of $\mathrm{AD}$ has been a priority of $\mathrm{AD}$ research worldwide. Based on understanding of disease mechanism, different therapeutic strategies involving synthetic and herbal approaches are being used against AD. Among the herbal extract, Ginkgo biloba extract (GBE) is one of the most investigated herbal remedy for cognitive disorders and Alzheimer's disease (AD). Standardized extract of Ginkgo biloba is a popular dietary supplement taken by the elderly population to improve memory and agerelated loss of cognitive function. Nevertheless, its efficacy in the prevention and treatment of dementia remains controversial. Specifically, the added effects of GBE in subjects already receiving "conventional" anti-dementia treatments have been to date very scarcely investigated. This review summarizes recent advancements in our understanding of the potential use of Ginkgo biloba extract in the prevention of $\mathrm{AD}$ including its antioxidant property. A better understanding of the mechanisms of action of GBE against $\mathrm{AD}$ will be important for designing therapeutic strategies, for basic understanding of the underlying neurodegenerative processes, and for a better understanding of the effectiveness and complexity of this herbal medicine.
\end{abstract}

Key Words Alzheimer's disease · Antioxidant - Dietary supplement - Ginkgo biloba extract · Herbal compounds · Neurodegenerative disease

\section{Introduction}

Alzheimer's disease (AD) is characterized by senile plaques and neurofibrillary tangles with progressive involvement of cognitive changes which primarily includes memory loss [1]. These aforementioned hallmark of AD therefore explains the need to decipher certain key questions in a way to understand disease etiology. For example, what factor/event induces the alterations in the processing of amyloid- $\beta$ protein

Sandeep Kumar Singh

sks.1247@gmail.com

George Perry

george.perry@utsa.edu

1 Indian Scientific Education and Technology Foundation, Lucknow 226002, India

2 School of Life Sciences, Jawaharlal Nehru University, New Delhi, India

3 School of Medicine, West Virginia University, Morgantown, USA

4 College of Sciences, The University of Texas at San Antonio, San Antonio, TX, USA precursor $(\mathrm{A} \beta \mathrm{PP})$ that lead to plaque formation and the hyperphosphorylation of tau protein that leads to tangles? The prevalence of $\mathrm{AD}$ varies among several different factors, including age, genetics, comorbidities, and education level [2]. There is no cure for AD; however, promising research and development for early detection and treatment is underway. Moreover, deducing an effective treatment method against AD still poses a significant clinical challenge. Several drug treatments are available to help prevent various symptoms in the disease, and researchers around the world are focusing on finding better treatments, preventive strategies, and ultimately a cure. Researchers are using different synthetic and/or herbal compounds to test their potential efficacy against AD [3-6]. In this milieu, polyphenolic compounds from medicinal plants are key sources of neuroprotective agents against $\mathrm{AD}$. Targeting the structure of these bioactive ingredients as templates for synthetic drugs offers a wide range of potential neuroprotective compounds [7, 8]. Natural polyphenolic compounds impart their antioxidant effect by reducing free radical species, metal bonding, and/or producing endogenous antioxidant capacity [9]. Thus, the antioxidant properties positively contribute to their neuroprotective 
effects. Furthermore, some of them have been shown to impact synthesis of endogenous antioxidant molecules in cells via triggering the Nrf/ARE pathway [10].

Ginkgo biloba's place of origin is believed to be remote mountainous valleys of Zhejiang province of eastern China $[11,12]$. Standardized Ginkgo biloba extract (GBE) derived from dried leaves of Ginkgo is used as a therapeutic drug for the treatment of memory impairment and dementia including Alzheimer's disease (AD) [13, 14]. A number of clinical studies showed amelioration of cognitive function in the elderly and in AD patients [15-19]; however, other reports do not support GBE in AD. The controversy regarding the benefits of GBE for different indications has been fortified after the publication of two major trials: i) the GEM study by DeKosky and colleagues [20] showed no favorable effect of GBE for the prevention of dementia onset in older people with or without mild cognitive impairment and ii) the study by McCarney and colleagues [21] indicated no evidence of effectiveness of GBE in mild to moderate dementia. Notably, multiple effects on apoptotic pathway and mitochondrial function that seems to be crucial for its valuable effects in $\mathrm{AD}$ were reported: improvement of energy metabolism, stabilization of mitochondrial membrane potential, inhibition of cytochrome c release, upregulation of anti-apoptotic Bcl-2 protein and downregulation of pro-apoptotic Bax protein and reduced level of caspase 9 and caspase 3 after oxidative stress, and decrease of apoptotic cell death [22-28]. The aim of this review is to summarize and to critically evaluate the evidence relating to the neuroprotective and antioxidant effects of the Ginkgo biloba extract (GBE) a commonly used extract in experimental and clinical studies.

\section{Origin and History of Ginkgo biloba}

Ginkgo biloba is the oldest living tree species in the world. The Ginkgo species dates all the way back to the Permian Period some 286 to 248 million years ago. Today, Ginkgo biloba is the only surviving member of the Ginkgo family. This survival is said to be owed to its extraordinary malleability, resistance to disease, and to Buddhist monks who cultivated and preserved the trees on sacred grounds [29]. Gingko was a favorite of Frank Lloyd Wright and soon made its approach into city landscapes across the USA [30]. The documented medicinal uses of Ginkgo in China can be tracked back nearly 5000 years, mainly for asthma treatment [31].

\section{Leaf Extract of Ginkgo biloba}

The leaves of the Ginkgo tree have a long history of being used for medicinal purposes. In the early 1970s, Dr. Willmar Schwabe Pharmaceuticals (Karlsruhe, Germany) effectively developed a method for the extraction and standardization of Ginkgo biloba extract preparation and produced highly concentrated and stable extracts from Ginkgo biloba leaves [32]. The standardized extract of Ginkgo biloba leaves (GBE) contains 6\% terpenoids (in which $3.1 \%$ are ginkgolides $\mathrm{A}, \mathrm{B}, \mathrm{C}$, and $\mathrm{J}$ and $2.9 \%$ is bilobalide), $24 \%$ flavonoid glycosides (containing quercetin, kaempferol, isorhamnetin etc.), and $5-10 \%$ organic acids (Figs. 1 and 2). The flavonoids and terpenoids are suggested to be the pharmacologically active constituents of GBE [33, 34]. Water solubility of GBE is on account of the presence of organic acid content [35]. Various preclinical research assessing GBE effects have been undertaken by the important studies of $Y$ Luo and others that suggest the neuroprotective effects of this herbal extract in cell and animal-based models [36-42]. GBE has been widely used in the treatment and prevention of neurodegenerative dementias associated with aging, Alzheimer's disease (AD), Parkinson's disease (PD), peripheral vascular diseases, and neurosensory problems (e.g., tinnitus) with mixed results $[30,43,44]$. GBE is used in an extensive range of disorders and diseases, including depressed mood, multi-infarct dementia, cerebral insufficiency (characterized by symptoms such as memory impairment, poor concentration, anxiety, and confusion), myocardial ischemia, stroke, thrombosis, and peripheral occlusive arterial disease (POAD). In addition, its effects on antidepressant-induced sexual dysfunction [45], traumatic brain injury, and hypertension have been studied [46].

\section{Individual Components of Ginkgo biloba}

GBE comprises different constituents (Fig. 1) like Trilactonicditerpenes, ginkgolides $\mathrm{A}, \mathrm{B}$, and $\mathrm{C}$ (ginkgolides $\mathrm{J}$ and $\mathrm{M}$, not shown, are present in lower concentrations). Flavonoids including quercetin, kaempferol, isorhamnetins, trilactonicsesquiterpene, and proanthocyanidins are also present. Other constituents such as glucose, rhamnose, hydroxykynurenic, kynurenic, protocatechuic, vanillic, and shikimic acids, D-glucaric acid, ginkgolic acid, and related alkyphenols have also been isolated. Ginkgolides have been specifically shown to act as platelet-activating factor (PAF) antagonists, inhibiting platelet aggregation and stimulating blood flow [47]. Flavonoids are known to act as major antioxidants among various polyphenol and also act as a heavy metal chelators due to their phenolic structures [48]. They have been clinically explored in inflammatory diseases [49] and cardiovascular disorders [50]. Additionally, GBE has shown neuroprotection and antiinflammatory properties in preclinical models of $\mathrm{AD}$ [51] and stroke [52].

\section{Pharmacological Importance}

Although Ginkgo has been around for over 200 million years, it is only during the last couple of decades that it has been well 
Fig. 1 Pictorial illustrations of the active components present in Ginkgo biloba extract (GBE). Note the multiple classes of bioactive agents

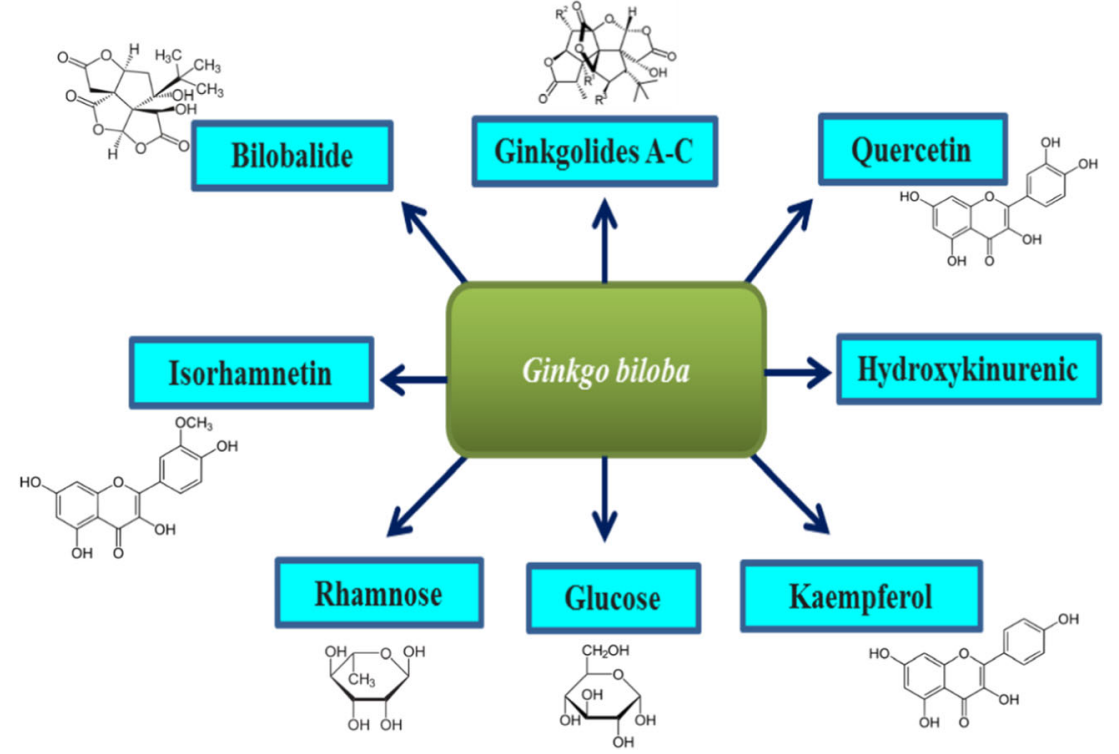

studied. Its amazing liveliness has fascinated an increasing exploration into potential application in food, health, and supplements. The important parts of Ginkgo tree having medicinal values are fresh or dried leaves and seeds. It contains large number of active compounds (Fig. 2), known to have pharmacological value. The active component in GBE from Ginkgo leaves improves blood circulation, reinforces the walls of the capillaries, discourages clot formation, and protects nerve cells from harm when devoid of oxygen. The leaf extracts are used to treat dementia disorders, such as concentration difficulties and memory impairment. The extract also possesses anti-asthmatic [53], antioxidant [54], wound healing [55], radical-scavenging [56], and neuroprotective properties against neurodegenerative disorders like AD [57, 58] and PD [59]. The benefits of antioxidants alone in reducing Alzheimer's or other diseases is clearly unproven, when in contrast, complex mixtures such as chocolate or blueberries have benefit due to the pleotropic effects. In addition, pure antioxidants may further disrupt tightly regulated stress responses.

Positive effect of Ginkgo biloba plant have been reported on Alzheimer's disease, memory enhancement, dementia of vascular origin, cognitive disorders, and its antioxidative effects in combination with other drugs, which enhance their effects or decrease their psychiatric side effects (Fig. 3) [49-62]. Ginkgo biloba can be used as a reinforcing antidepressant agent and a neuroprotective drug in brain injuries [63]. This plant modifies the cerebral blood flow and may help to reduce fatigue and inattention [64]. Other studies showed its effect on several different neurotransmitter systems of central nervous system $[65,66]$. The anti-anxiety and mild anti-depression property of GBE is
Fig. 2 Schematic chart showing various active components found in GBE. The wide-raging activities found in GBE make a single mechanism of action difficult and rather argue for pleotropic effects

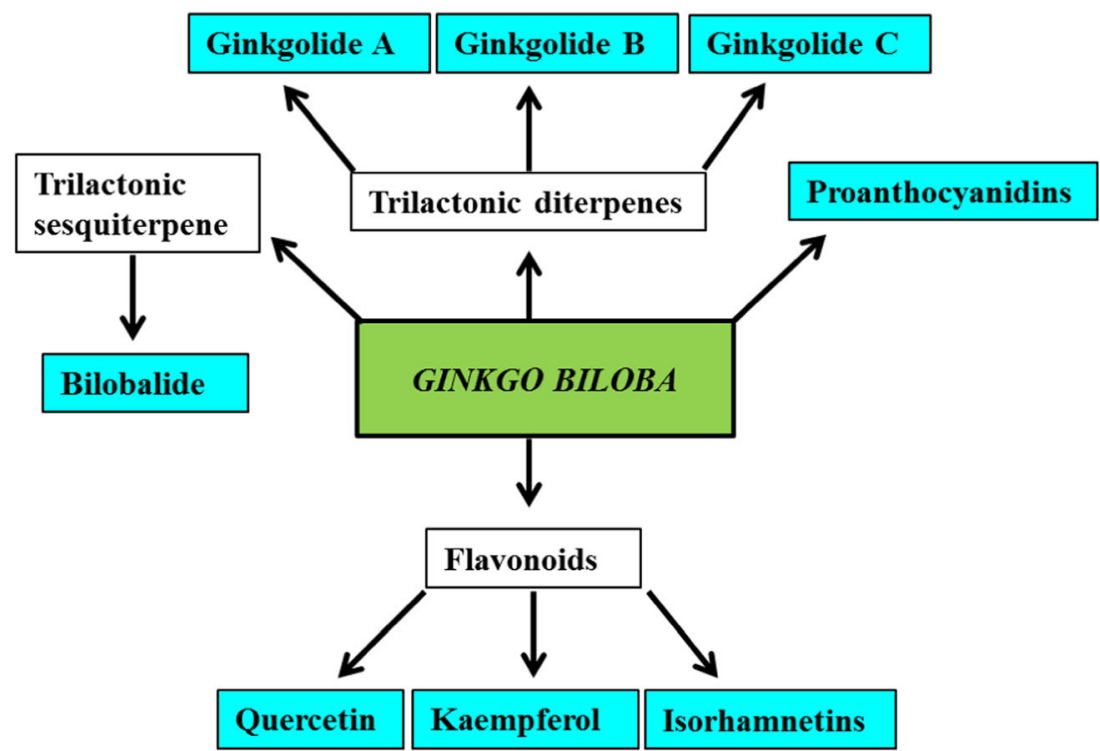


Fig. 3 GBE has an array of activities relevant to neurological functions. The range of activities underlies the pleotropic effects of GBE

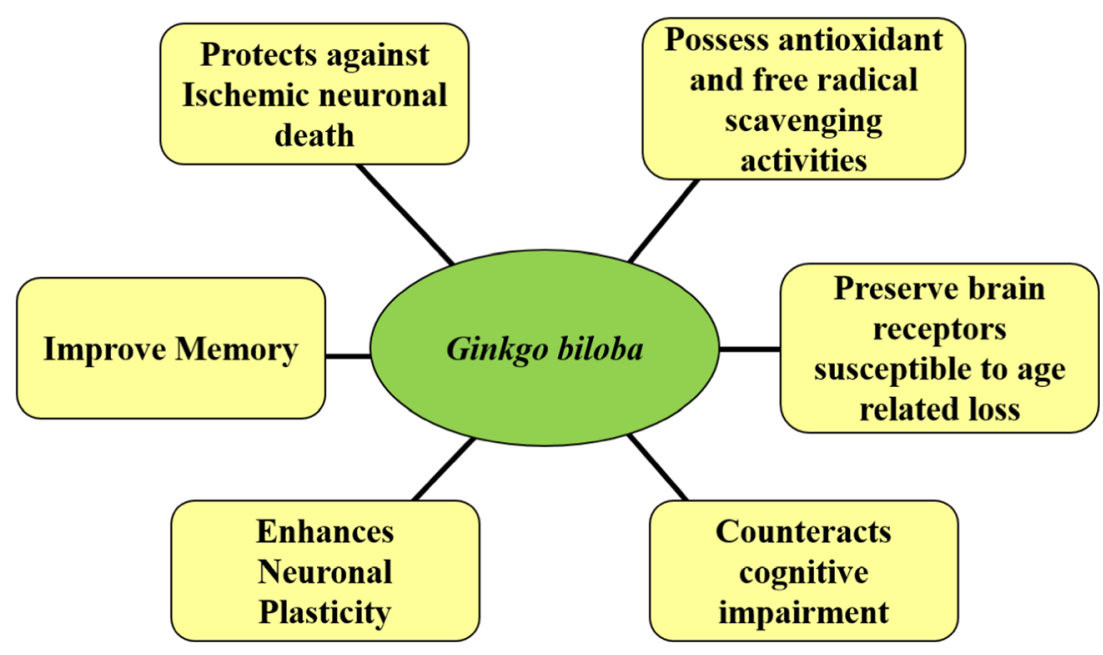

accounted from the reversible inhibition of two MAOA and MAOB enzymes [67], while the antioxidant, anti-inflammatory, and neuroprotective effects are contributed mainly by the flavonoid and terpenoid content in GBE. Ginkgo biloba has a positive effect on cognitive and neurological function by vascular flow regulation and platelet-activating antagonism factors that protect the brain from ischemic injuries [64]. Alkaloid ketones, amino acids, cyanogenic glycosides, and phenols, abundant in this plant extract, are active ingredients responsible for its therapeutic effects [64]. Ginkgo biloba has positive effects on psychosis, anxiety, schizophrenia, and depression [68]. It stimulates the cerebral blood circulation and improves problems caused by the failure of blood circulation in the brain including anxiety, stress, low memory, hearing problems, low concentration, thinking, social behavior, and dementia in Alzheimer's disease [64].

\section{Neuroprotective Effects of Ginkgo biloba Extract}

The neuroprotective effect of GBE has been validated in several in vitro and in vivo models studies [69]. In vitro studies revealed that GBE protected cultured neurons against death induced by hydrogen peroxide [70-76], hypoxia [77], glutamate [78, 79], verapamil [79], amyloid- $\beta$ [80, 81], 1-methyl-4-phenyl-1,2,3,6tetrahydropyridine (MPTP, [82], nitric oxide (NO), [83], and cyanide [78]. Also, in in vivo effect, reduction of neuronal damage by EGb761 (10-100 mg/kg, p.o. (per os), or i.p. (intraperitoneally)) has been observed after transient middle cerebral artery occlusion (MCAO) in rats [78, 84] and gerbils [85-87]; focal cerebral ischemia in mice and rats [78]; hypoxia [88]; heat stress [89]; subchronic cold stress [90]; and amphetamine-induced behavioral sensitization [91], and in a transgenic mouse model of amyotrophic lateral sclerosis [92]. The ginkgolides (1-100 $\mu \mathrm{M}$ in vitro or $50-100 \mathrm{mg} / \mathrm{kg}$ in vivo), bilobalide (25-100 $\mu \mathrm{M}$ in vitro or $10 \mathrm{mg} / \mathrm{kg}$ in vivo), and in some cases also the flavonoid fraction $(25-100 \mu \mathrm{g} / \mathrm{ml}$ in vitro or $40-100 \mathrm{mg} / \mathrm{kg}$ in vivo) have been shown to contribute to the neuroprotective effect of EGb 761. Besides free radical-scavenging property of EGb 761, it has also been shown to affect the transcription of several genes associated to oxidative stress regulation [93]. This is an important property of EGB 761 as it may help in improved cellular tolerance against oxidative stress thereby protecting neuronal cell against oxidative damage commonly associated to neurodegenerative diseases like $\mathrm{AD}$ and $\mathrm{PD}$ condition.

\section{Effect of GBE against A $\beta$ Aggregation}

The accumulation of $\mathrm{A} \beta$ plaques is a hallmark of $\mathrm{AD}$ [94]. Recently, the use of GBE in the neuroprotection against the $\mathrm{A} \beta$-induced neurotoxicity has received much attention among scientific community. Several recent studies showed that GBE protects against $A \beta$-induced neurotoxicity by obstruction of $\mathrm{A} \beta$-induced events, such as glucose uptake, reactive oxygen species (ROS) accumulation, activation of AKT, mitochondrial dysfunction, JNK and ERK 1/2 pathways, and apoptosis (Fig. 4) [95-97]. It has been reported that GBE inhibits the production of $\mathrm{A} \beta$ in brain by lowering the levels of circulating free cholesterol, as A $\beta$ PP processing and amyloidogenesis are supposed to be affected by free circulating and intracellular cholesterol levels [98-102]. Despite this evidence, further investigations are needed to identify the major constituents responsible for this anti-amyloidogenic effect. GBE could also interfere with the $A \beta$ oligomer formation $[26,99]$. It is well known that the $\beta$-sheet structure of $A \beta$ oligomers is primarily accountable for $A \beta$ neurotoxicity and may also help $A \beta$ discharge from clearance via proteolytic cleavage [99, 103-105]. Thus, preventing the formation of $\beta$-sheet structure of $A \beta$ oligomers may also be a very prominent strategy to prevent $\mathrm{A} \beta$ toxicity. Apart from self oligomerization of the $A \beta$, the interaction of $\mathrm{A} \beta$ with different transition metal ions, notably copper, iron, and zinc, could influence the oligomerization of $\mathrm{A} \beta$. GBE has iron chelating property which may also inhibit 
Fig. 4 Pictorial illustration of $\mathrm{A} \beta$-induced damage through metal dyshomeostasis, redox imbalance, mitochondrial dysfunction which finally leads to neuronal apoptosis, and GBE role in its alleviation. Upward arrows represent upregulation. Downward arrows represent downregulation

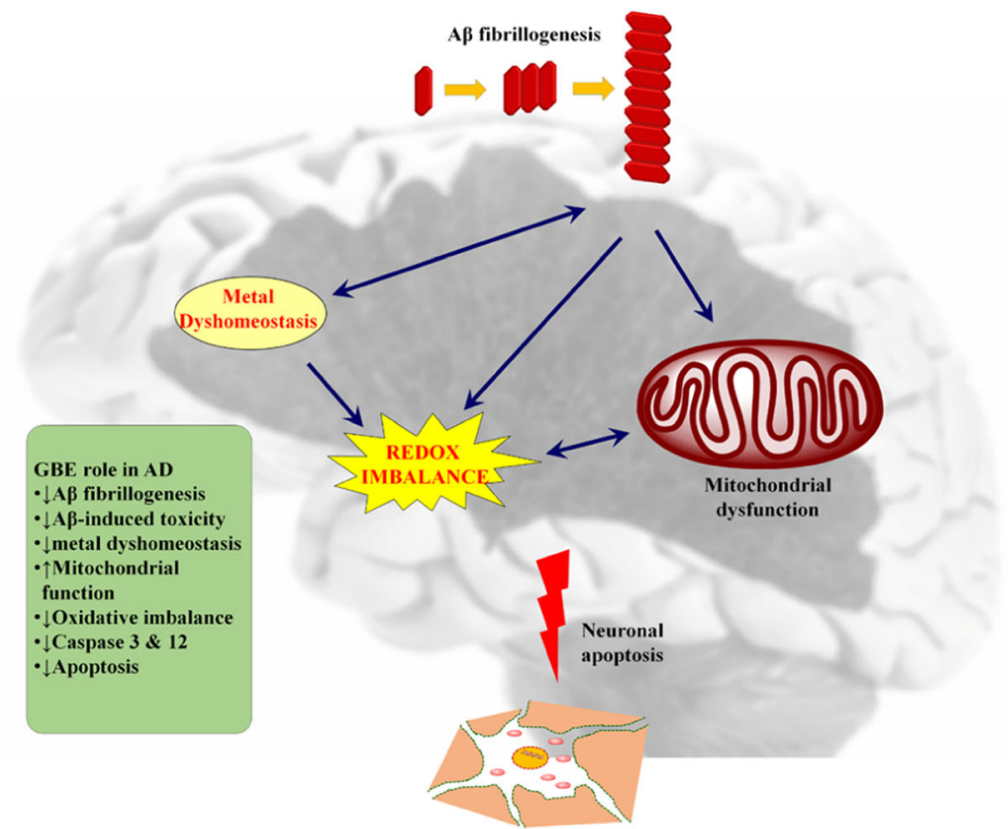

$\mathrm{A} \beta$ fibril formation [26, 99]. Collectively, we can say that GBE is highly effective and prominent against AD by effecting in several ways as mentioned in Fig. 4.

Transthyretin has been shown to prevent $A \beta$ aggregation in vitro by sequestering $A \beta$ monomers $[96,106]$. GBE may also prevent the $A \beta$ fibril formation by increasing gene expression of transthyretin [107], The anti-A $\beta$ effect of GBE on $\mathrm{A} \beta$ aggregation was also observed with flavonoid compounds, ginkgolide J, and bilobalide [26, 99]. Further, GBE has also been shown to regulate mitochondrial oxidative phosphorylation (OXPHOS) against $\mathrm{A} \beta$-induced oxidative stress thereby helping in maintaining the ROS/RNS (reactive oxygen species/reactive nitrogen species) equilibrium in cells [108]. Studies show that GBE imparts beneficial effects on the cellular OXPHOS functioning thereby helping in amelioration of mitochondrial function against $A \beta$-induced toxicity [109]. Although studies show promising results for GBE against $A \beta$-induced toxicity, more studies are required to decipher the mechanism of action of individual components of GBE against $A \beta$-induced toxicity in $\mathrm{AD}$.

\section{Antioxidant Activity}

Oxidative stress disequilibrium has been one of the hallmark signs involved in $\mathrm{AD}$ pathogenesis [110-113]. Several in vitro and in vivo studies support the beneficial action of GBE mainly due to its free radical-scavenging action [38], as is evident from a study in which pretreating cerebellar granule cells with GBE effectively diminished the oxidative damage triggered by $\mathrm{H}_{2} \mathrm{O}_{2} / \mathrm{FeSO}_{4}$ [114]. Further, in studies from AD models, $\mathrm{A} \beta$ expressing transgenic Caenorhabditis elegans [115] and $\mathrm{A} \beta$ - expressing neuroblastoma cell line N2a [38], GBE was found to significantly attenuate the basal as well as the induced levels of $\mathrm{H}_{2} \mathrm{O}_{2}$-related reactive oxygen species (ROS) $[38,115]$. In addition to direct reduction of ROS, GBE may also be helpful in upregulation of antioxidant enzymes and protein level [102]. For example, superoxide dismutase (SOD) and catalase activity was found to be elevated in rat hippocampus and rat ileum supplemented with GBE $[36,116,117]$. Glutathione (GSH) reductase and gamma-glutamylcysteinyl synthetase, which are two important enzymes used in the reduction step of synthesis of GSH, were also enhanced by GBE $[36,118,119]$. The main active and responsible fraction for antioxidant activity in GBE extract is flavonoids. Previous studies proposed that the flavonoid fraction's antioxidant property is ROS scavenging, increase in antioxidant proteins such as SOD and GSH, and chelating prooxidant transitional metal ions [38, 97, 120, 121]. Quercetin [122] and myricetin are the two flavonoid structures which effectively inhibit tert-butylhydroperoxide oxidation [36]. In contrast, the antioxidant activity of terpene lactones still remains to be deciphered [36]. The discrepancy on the antioxidant activity of the terpene lactones may be explained as being due to differences in the type of oxidative stress used as well as the experimental models [36].There are contradictory data in context to superoxide-scavenging activity of ginkgolides $\mathrm{B}, \mathrm{C}$, and $\mathrm{J}$ and bilobalide [36, 123, 124].

\section{Conclusions}

Ginkgo biloba extract (GBE) is used effectively for treatment of many human disorders including brain function. Various research studies were carried out on Ginkgo biloba extract 
and found its phytomedicinal properties and its efficacy under many disease conditions. Many research reports effective use of GBE in cerebrovascular insufficiency, peripheral artery insufficiency, multi-infarct dementia, memory impairment in the elderly, Alzheimer's disease, resistant depression, asthma, and venous insufficiency. GBE for schizophrenia, tinnitus, brain syndrome, vertigo of undetermined origin, and PMS, although less supported, still requires further study. Various in vivo and in vitro preclinical studies support the view that standardized Ginkgo biloba extract EGb761 may be effective in the treatment and prevention of $\mathrm{AD}$ and other age-related, neurodegenerative disorders. Anti-oxidation, anti-inflammation, antiapoptosis, defense against mitochondrial dysfunction, amyloidogenesis and $A \beta$ aggregation, modulation of phosphorylation of tau protein, ion homeostasis, and even induction of growth factors are possible mechanisms of action of GBE (Fig. 4). However, the clinical efficacy of EGb761 still remains elusive. Multiple factors such as population sensitivity, severity of impairment, type of assessments used to measure efficacy, and doses were suggested to be able to interfere with EGb761's efficacy in clinical practice. Regarding these factors, basic scientific reports give useful information that may help to modify the clinical efficacy of this drug. Overall, a better understanding of the mechanisms underlying the neuroprotective effects of EGb761 may contribute to better understanding of the effectiveness and complexity of this drug and may also be helpful for designing therapeutic strategies in future clinical practice.

Acknowledgments This work was performed with resources from the following non-profit organizations: Indian Scientific Education and Technology Foundation (ISET Foundation), Lucknow, India, the Alzheimer's Association, and the National Institute of Health (GIZMD007591), USA.

Required Author Forms Disclosure forms provided by the authors are available with the online version of this article.

\section{Compliance with Ethical Standards}

Conflict of Interest The authors declare that they have no conflict of interest.

\section{References}

1. Cummings JL, Vinters HV, Cole GM, Khachaturian ZS. Alzheimer's disease: etiologies, pathophysiology, cognitive reserve, and treatment opportunities. Neurology 1998;51 (1 Suppl 1):S2-17.

2. Barnes DE, Yaffe K. The projected effect of risk factor reduction on Alzheimer's disease prevalence. Lancet Neurol 2011;10 (9): 819-28.

3. Singh SK, Sinha P, Mishra L, et al. Neuroprotective role of a novel copper chelator against induced neurotoxicity. Int J Alzheimers Dis $2013 ; 2013$.
4. Kumar A, Srivastava S, Tripathi S, Singh SK, Srikrishna S, Sharma A. Molecular insight into amyloid oligomer destabilizing mechanism of flavonoid derivative 2-(4' benzyloxyphenyl)-3-hydroxy-chromen-4-one through docking and molecular dynamics simulations. J Biomol Struct Dyn 2016;34(6):1252-63.

5. Singh SK, Gaur R, Kumar A, Fatima R, Mishra L, Srikrishna S. The flavonoid derivative 2-(4' benzyloxyphenyl)-3-hydroxy-chromen-4-one protects against $A \beta 42$-induced neurodegeneration in transgenic drosophila: insights from in silico and in vivo studies. Neurotox Res 2014;26(4):331-50.

6. Klafki HW, Staufenbiel M, Kornhuber J, Wiltfang J. Therapeutic approaches to Alzheimer's disease. Brain 2006;129(11):2840-55.

7. Newman DJ, Cragg GM. Natural products as sources of new drugs over the 30 years from 1981 to 2010 . J Nat Prod 2012;75(3):311-35.

8. Asadi S, Ahmadiani A, Esmaeili MA, Sonboli A, Ansari N, Khodagholi $\mathrm{F}$. In vitro antioxidant activities and an investigation of neuroprotection by six Salvia species from Iran: a comparative study. Food Chem Toxicol 2010;48(5):1341-9.

9. Singh SK, Srivastav S, Yadav AK, et al. Overview of Alzheimer's disease and some therapeutic approaches targeting $A \beta$ by using several synthetic and herbal compounds. Oxidative Med Cell Longev 2016; 2016.

10. Dumont M, Beal MF. Neuroprotective strategies involving ROS in Alzheimer disease. Free Radic Biol Med 2011;51(5):1014-26.

11. Kubitzki K. In: Kramer K, Greech PS, editors. The families and genera of vascular plants - pteridophytes and gymnosperms. Berlin: Springer Verlag; 1990. p. 284.

12. Hori T, Ridge RW, Tulecke W, Del Tredici P, TrémouillauxGuiller J, Tobe H, editors. Ginkgo biloba a global treasure: from biology to medicine Springer Science \& Business Media; 2012.

13. Vellas B, Coley N, Ousset PJ, Berrut G, Dartigues JF, Dubois B, Grandjean H, Pasquier F, Piette F, Robert P, Touchon J. Long-term use of standardised Ginkgo biloba extract for the prevention of Alzheimer's disease (GuidAge): a randomised placebo-controlled trial. Lancet Neurol 2012;11(10):851-9.

14. Oken BS, Storzbach DM, Kaye JA. The efficacy of Ginkgo biloba on cognitive function in Alzheimer disease. Arch Neurol 1998;55(11):1409-15.

15. Kanowski S, Herrmann WM, Stephan K, Wierich W, Horr R. Proof of efficacy of the ginkgo biloba special extract EGb 761 in outpatients suffering from mild to moderate primary degenerative dementia of the Alzheimer type or multi-infarct dementia. Pharmacopsychiatry 1996;29:47-56.

16. Le Bars PL, Katz MM, Berman N, et al. A placebo-controlled, double-blind, randomized trial of an extract of Ginkgo biloba for dementia. North American EGb Study Group. JAMA 1997;278: 1327-1332.

17. Napryeyenko O, Borzenko I. Ginkgo biloba special extract in dementia with neuropsychiatric features. A randomised, placebocontrolled, double-blind clinical trial. Arzneimittelforschung 2007;57:4-11.

18. Yancheva S, Ihl R, Nikolova G, et al. Ginkgo biloba extract EGb $761(\mathrm{R})$, donepezil or both combined in the treatment of Alzheimer's disease with neuropsychiatric features: a randomised, double-blind, exploratory trial. Aging Ment Health 2009;13:183190.

19. Mix JA, Crews WD, Jr. A double-blind, placebo-controlled, randomized trial of Ginkgo biloba extract EGb 761 in a sample of cognitively intact older adults: neuropsychological findings. Hum Psychopharmacol 2002;17:267-277.

20. DeKosky ST, Williamson JD, Fitzpatrick AL, Kronmal RA, Ives DG, Saxton JA, Lopez OL, Burke G, Carlson MC, Fried LP, Kuller LH. Ginkgo biloba for prevention of dementia: a randomized controlled trial. Jama 2008;300(19):2253-62. 
21. McCarney R, Fisher P, Iliffe S, van Haselen R, Griffin M, van der Meulen J, Warner J. Ginkgo biloba for mild to moderate dementia in a community setting: a pragmatic, randomised, parallel-group, double-blind, placebo-controlled trial. Int J Geriatr Psychiatry 2008;23(12):1222-30.

22. Schindowski K, Leutner S, Kressmann S, Eckert A, Muller WE. Age-related increase of oxidative stress-induced apoptosis in mice prevention by Ginkgo biloba extract (EGb761). J Neural Transm 2001;108:969-978.

23. Smith JV, Burdick AJ, Golik P, et al. Anti-apoptotic properties of Ginkgo biloba extract EGb 761 in differentiated PC12 cells. Cell MolBiol (Noisy-le-grand) 2002;48:699-707.

24. Leuner K, Hauptmann S, Abdel-Kader R, et al. Mitochondrial dysfunction: the first domino in brain aging and Alzheimer's disease? Antioxid Redox Signal 2007;9:1659-1675.

25. Abdel-Kader R, Hauptmann S, Keil U, et al. Stabilization of mitochondrial function by Ginkgo biloba extract (EGb 761). Pharmacol Res 2007;56:493-502.

26. Luo Y, Smith JV, Paramasivam V, et al. Inhibition of amyloid-beta aggregation and caspase- 3 activation by the Ginkgo biloba extract EGb761. Proc Natl Acad Sci U S A 2002;99:12197-12202.

27. Eckert A, Keil U, Scherping I, Hauptmann S, Muller WE. Stabilization of Mitochondrial Membrane Potential and Improvement of Neuronal Energy Metabolism by Ginkgo Biloba Extract EGb 761. Ann N Y Acad Sci 2005;1056:474-485.

28. Eckert A, Keil U, Kressmann S, et al. Effects of EGb 761 Ginkgo biloba extract on mitochondrial function and oxidative stress. Pharmacopsychiatry 2003;36(Suppl 1)S15-23.

29. Kwant, Cor. Hiroshima: A Bombed Ginkgo. The Ginkgo Pages http://www.xs4all.nl/ kanten/history.htm. Internet Explorer April 18, 2006.

30. Wanadoo. http://perso.wanadoo.fr/ginkgo.dm/index.html. Internet Explorer April 18, 2006.

31. Griggs B. GREEN PHARMACY: The History and Evolution of Western Herbal Medicine. New York: Viking Press, 1981) p. 326.

32. Le Bars PL. Magnitude of effect and special approach to Ginkgo biloba extract EGb761 in cognitive disorders. Pharmacopsychiatry 2003;36:S44-S49.

33. Smith PF, Maclennan K, Darlington CL. The neuroprotective properties of the Ginkgo biloba leaf a review of the possible relationship to platelet-activating factor (PAF). J Ethnopharmacol 1996;50:131-139.

34. Shi C, Zhao L, Zhu B, Li Q, Yew DT, Yao Z, Xu J. Protective effects of Ginkgo biloba extract (EGb761) and its constituents quercetin and ginkgolide B against beta-amyloid peptideinduced toxicity in SH-SY5Y cells. Chem Biol Interact 2009;181:115123.

35. Maclennan KM, Darlington CL, Smith PF. The CNS effects of Ginkgo biloba extracts and ginkgolide B. Prog Neurobiol 2002;67:235-257.

36. Ahlemeyer B, Krieglstein J. Neuroprotective effects of Ginkgo biloba extract. Cell Mol Life Sci 2003;60:1779-1792.

37. Christen Y. Ginkgo biloba and neurodegenerative disorders. Front Biosci. 2004;9:3091 3104.

38. Smith JV, Luo Y. Studies on molecular mechanisms of Ginkgo biloba extract. Appl Microbiol Biotechnol 2004;64:465-472.

39. Luo Y. Ginkgo biloba neuroprotection: Therapeutic implications in Alzheimer's disease. J Alzheimers Dis 2001;3:401-407.

40. Saleem S, Zhuang H, Biswal S, Christen Y, Doré S. Ginkgo biloba extract neuroprotectiveaction is dependent on heme oxygenase 1 in ischemic reperfusion brain injury. Stroke 2008;39:3389-3396.

41. Ponto LL, Schultz SK. Ginkgo biloba extract: Review of CNS effects. Ann Clin Psychiatry 2003;15:109-119.

42. Luo Y. Alzheimer's disease, the nematode Caenorhabditis elegans, and ginkgo biloba leaf extract. Life Sci 2006;78:2066-2072.
43. Holstein N. Ginkgo special extract EGb 761 in tinnitus therapy. An overview of results of completed clinical trials. Fortschr Med Orig 2001;118:157-164.

44. Schneider B. Ginkgo biloba extract in peripheral arterial diseases: Meta-analysis of controlled clinical studies. Arzneimittelforschung 1992;42:428-436.

45. Wheatley D. Ginkgo biloba in the treatment of sexual dysfunction due to antidepressant drugs. Hum Psychopharmacol 1999;14: 512-513.

46. Diamond BJ, Shiflett SC, Feiwel N, et al. Ginkgo biloba extract: mechanisms and clinical indications. Arch Phys Med Rehabil 2000;81:668-678

47. Yue TL, Feuerstein GZ. Platelet-activating factor: a putative neuromodulator and mediator in the pathophysiology of brain injury. Crit Rev Neurobiol 1994;8:11-24.

48. Gohil K, Moy RK, Farzin S, Maguire JJ, Packer L. mRNA expression profile of a human cancer cell line in response to Ginkgo biloba extract: induction of antioxidant response and the Golgi system. Free Radic Res 2000;33:831-49.

49. Dower JI, Geleijnse JM, Gijsbers L, Schalkwijk C, Kromhout D, Hollman PC. Supplementation of the pure flavonoids epicatechin and quercetin affects some biomarkers of endothelial dysfunction and inflammation in (Pre)hypertensive adults: a randomized double-blind, placebo-controlled, crossover trial. J Nutr 2015;145: 1459-63.

50. Dower JI, Geleijnse JM, Gijsbers L, Zock PL, Kromhout D, Hollman PC. Effects of the pure flavonoids epicatechin and quercetin on vascular function and cardiometabolic health: a randomized, double-blind, placebo-controlled, crossover trial. Am J Clin Nutr 2015;101:914-21.

51. Yin $\mathrm{Y}, \mathrm{Ren} \mathrm{Y}, \mathrm{Wu} \mathrm{W}$, et al. Protective effects of bilobalide on $\mathrm{A} \beta(25-35)$ induced learning and memory impairments in male rats. Pharmacol Biochem Behav 2013;106:77-84.

52. Jiang M, Li J, Peng Q, et al. Neuroprotective effects of bilobalide on cerebral ischemia and reperfusion injury are associated with inhibition of pro-inflammatory mediator production and downregulation of JNK $1 / 2$ and p38 MAPK activation. J Neuroinflammation 2014;11:167.

53. Mahmoud F, Abul H, Onadeko B, Khadadah M, Haines D, Morgan G. In vitro effects of Ginkgolide B on lymphocyte activation in atopic asthma: comparison with cyclosporin A. Jpn J Pharmacol 2000;83(3):241-5.

54. Nakanishi K. Terpene trilactones from Gingko biloba: from ancient times to the 21st century. Bioorg Med Chem 2005;13(17): 4987-5000.

55. Bairy KL. Wound healing potentials of plant products. J Nat Rem 2002;2(1):11-20.

56. Louajri A, Harraga S, Godot V, Toubin G, Kantelip JP, Magnin P. The effect of ginkgo biloba extract on free radical production in hypoxic rats. Biol Pharm Bull 2001;24(6):710-2.

57. Zeng K, Li M, Hu J, et al. Ginkgo biloba extract EGb761 attenuates Hyperhomocysteinemia-induced AD like tau hyperphosphorylation and cognitive impairment in rats. Curr Alzheimer Res 2018;15(1):89-99

58. Yuan Q, Wang CW, Shi J, Lin ZX. Effects of Ginkgo biloba on dementia: An overview of systematic reviews. J Ethnopharmacol 2017;195:1-9

59. Srivastav S, Fatima M, Mondal AC. Important medicinal herbs in Parkinson's disease pharmacotherapy. Biomed Pharmacother 2017;92:856-63.

60. Smith TC, Ryan MA, Smith B, et al. Complementary and alternative medicine use among US Navy and Marine Corps personnel. BMC Complement Altern Med 2007;7:16.

61. DeFeudis FV, Drieu K. Ginkgo biloba extract (EGb 761) and CNS functions: basic studies and clinical applications. Curr Drug Targets 2000;1:25-58. 
62. Werneke U, Turner T, Priebe S. Complementary medicines in psychiatry: review of effectiveness and safety. Br J Psychiatry 2006;188:109-21.

63. Hechtman L. Attention -deficit / Hyperactivity disorder. In: Sadock BJ, Sadock VA, eds. Comprehensive Text Book of Psychiatry. 8th ed. Philadelphia: Lippincott Williams \& Wilkins;2005.

64. Noorbala AA, Akhondzadeh S. AttentionDeficit/Hyperactivity Disorder: Etiology and Pharmacotherapy. Arch Iran Med 2006;9:374-80.

65. Himi T, Saito H, Nishiyama N. Effect of ginseng saponins on survival of cerebral cortex neurons in cell cultures. Chem Pharm Bull (Tokyo) 1989;37:481-4.

66. Garg RK, Nag D, Agrawal A. A double blind placebo controlled trial of ginkgo biloba extract in acute cerebral ischaemia. J Assoc Physicians India 1995;43:760-3.

67. White HL, Scates PW, Cooper BR. Extracts of Ginkgo biloba leaves inhibit monoamine oxidase. Life Sci 1996;58:1315-21.

68. Kumar Singh S, Barreto E G, Aliev G, Echeverria V. Ginkgo biloba as an alternative medicine in the treatment of anxiety in dementia and other psychiatric disorders. Curr Drug Metab 2017;18(2):112-9.

69. Ahlemeyer B, Krieglstein J. Neuroprotective effects of the Ginkgo biloba extract. In: Phytomedicine of Europe: Chemistry and Biological activity, ACS Symposium Series. 1998.

70. Ni Y, Zhao B, Hou J, Xin W. Preventive effect of Ginkgo biloba extract on apoptosis in rat cerebellar neuronal cells induced by hydroxyl radicals. Neurosci Lett 1996;214(2-3):115-8.

71. Oyama Y, Chikahisa L, Ueha T, Kanemaru K, Noda K. Ginkgo biloba extract protects brain neurons against oxidative stress induced by hydrogen peroxide. Brain Res 1996;712(2):349-52.

72. Chen C, Wei T, Gao Z, et al. Different effects of the constituents of EGb761 on apoptosis in rat cerebellar granule cells induced by hydroxyl radicals. IUBMB Life 1999;47(3):397-405.

73. Song W, Guan HJ, Zhu XZ, Chen ZL, Yin ML, Cheng XF. Protective effect of bilobalide against nitric oxide-induced neurotoxicity in PC12 cells. Acta Pharmacol Sin 2000;21(5):415-20.

74. Xin W, Wei T, Chen C, Ni Y, Zhao B, Hou J. Mechanisms of apoptosis in rat cerebellar granule cells induced by hydroxyl radicals and the effects of EGb761 and its constituents. Toxicology 2000;148(2-3):103-10.

75. Zhou LJ, Zhu XZ. Reactive oxygen species-induced apoptosis in PC12 cells and protective effect of bilobalide. J Pharmacol Exp Ther 2000;293(3):982-8.

76. Guidetti C, Paracchini S, Lucchini S, Cambieri M, Marzatico F. Prevention of neuronal cell damage induced by oxidative stress invitro: effect of different Ginkgo biloba extracts. J Pharm Pharmacol 2001;53(3):387-92.

77. Klein J, Chatterjee SS, Löffelholz K. Phospholipid breakdown and choline release under hypoxic conditions: inhibition by bilobalide, a constituent of Ginkgo biloba. Brain Res 1997;755(2):347-50.

78. Krieglstein J, Ausmeier F, El-Abhar H, et al. Neuroprotective effects of Ginkgo biloba constituents. Eur J Pharm Sci 1995;3(1): 39-48.

79. Zhu L, Gao J, Wang Y, Zhao XN, Zhang ZX. Neuron degeneration induced by verapamil and attenuated by EGb761. J Basic Clin Physiol Pharmacol 1997;8(4):301-14.

80. Bastianetto S, Ramassamy C, Doré S, Christen Y, Poirier J, Quirion R. The ginkgo biloba extract (EGb 761) protects hippocampal neurons against cell death induced by $\beta$-amyloid. Eur $\mathrm{J}$ Neurosci 2000;12(6):1882-90.

81. Zhou LJ, Song W, Zhu XZ, Chen ZL, Yin ML, Cheng XF. Protective effects of bilobalide on amyloid beta-peptide 25-35induced PC12 cell cytotoxicity. Acta Pharmacol Sin 2000;21(1): 75-9.
82. Yang SF, Wu Q, Sun AS, Huang XN, Shi JS. Protective effect and mechanism of Ginkgo biloba leaf extracts for Parkinson disease induced by 1-methyl-4-phenyl-1, 2, 3, 6-tetrahydropyridine. Acta Pharmacol Sin 2001;22(12):1089-93.

83. Bastianetto S, Zheng WH, Quirion R. The Ginkgo biloba extract (EGb 761) protects and rescues hippocampal cells against nitric oxide-induced toxicity: involvement of its flavonoid constituents and protein kinase C. J Neurochem 2000;74(6):2268-77.

84. Zhang WR, Hayashi T, Kitagawa H, et al. Protective effect of ginkgo extract on rat brain with transient middle cerebral artery occlusion. Neurol Res 2000;22(5):517-32.

85. Rabin O, Drieu K, Grange E, Chang MC, Rapoport SI, Purdon $\mathrm{AD}$. Effects ofEGb 761 on fatty acid reincorporation during reperfusion following ischemia in the brain of the awake gerbil. Mol Chem Neuropathol 1998;34(1):79-101.

86. Calapai G, Crupi A, Firenzuoli F, et al. Neuroprotective effects of Ginkgo biloba extract in brain ischemia are mediated by inhibition of nitric oxide synthesis. Life Sci 2000;67(22):2673-83.

87. Chandrasekaran K, Mehrabian Z, Spinnewyn B, Drieu K, Fiskum G. Neuroprotective effects of bilobalide, a component of the Ginkgo biloba extract (EGb 761), in gerbil global brain ischemia. Brain Res 2001;922(2):282-92.

88. Oberpichler H, Beck T, Abdel-Rahman MM, Bielenberg GW, Krieglstein J. Effects of Ginkgo biloba constituents related to protection against brain damage caused by hypoxia. Pharmacol Res Commun 1988;20(5):349-68.

89. Sharma HS, Drieu K, Alm P, Westman J. Role of nitric oxide in blood-brain barrier permeability, brain edema and cell damage following hyperthermic brain injury. In: An experimental study using EGB-761 and Gingkolide B pretreatment in the rat. InBrain Edema XI 2000 (pp. 81-86). Vienna: Springer.

90. Bolaños-Jiménez F, de Castro RM, Sarhan H, Prudhomme N, Drieu K, Fillion G. Stress-induced 5-HT1A receptor desensitization: protective effects of Ginkgo biloba extract (EGb 761). Fundam Clin Pharmacol 1995;9(2):169-74.

91. Trovero F, Brochet D, Tassin JP, Drieu K. Ginkgo biloba extract EGb761 reduces the development of amphetamine-induced behavioral sensitization: effects on hippocampal type II corticosteroid receptors. Brain Res 1999;818(1):135-9.

92. Ferrante RJ, Klein AM, Dedeoglu A, Beal MF. Therapeutic efficacy of EGb761 (Gingko biloba extract) in a transgenic mouse model of amyotrophic lateral sclerosis. J Mol Neurosci 2001;17(1):89-96.

93. Gohil, K.; Packer, L. Global gene expression analysis identifies cell and tissue specific actions ofGinkgo biloba extract, EGb 761. Cell Mol Biol 2002, 48, 625-631.

94. Gerlai, R. Alzheimer's disease: Beta-amyloid hypothesis strengthened! Trends Neurosci 2001, 24,199.

95. Shi C, Zhao L, Zhu B, et al. Protective effects of Ginkgo bilobaextract (EGb761) and its constituents quercetin and ginkgolide B against beta-amyloid peptideinduced toxicity in SH-SY5Y cells. Chem Biol Interact 2009;181:115-123.

96. Bastianetto S, Ramassamy C, Doré S, Christen S, Poirier J, Quirion R. The Ginkgo bilobaextract (EGb 761) protects hippocampal neurons against cell death induced by beta-amyloid. Eur J Neurosci 2000, 12, 1882-1890.

97. Smith JV, Luo Y. Elevation of oxidative free radicals in Alzheimer's disease models can be attenuated by Ginkgo biloba extract EGb 761. J Alzheimers Dis 2003, 5, 287-300.

98. Yao ZX, Han Z, Drieu K, Papadopoulos V. Ginkgo biloba extract (EGb 761) inhibits betaamyloid production by lowering free cholesterol levels. J Nutr Biochem 2004, 15, 749-756.

99. Ramassamy C. Emerging role of polyphenolic compounds in the treatment of neurodegenerative diseases: A review of their intracellular targets. Eur J Pharmacol 2006, 545, 51-64. 
100. Bodovitz, S.; Klein, W.L. Cholesterol modulates alpha-secretase cleavage of amyloid precursorprotein. J Biol Chem 1996, 271, 4436-4440.

101. Howland DS, Trusko SP, Savage MJ, et al. Modulation of secreted beta-amyloidprecursor protein and amyloid beta-peptide in brain by cholesterol. J Biol Chem 1998;273:16576-16582.

102. Simons M, Keller P, de Strooper B, Beyreuther K, Dotti CG, Simons K. Cholesterol depletion inhibits the generation of betaamyloid in hippocampal neurons. Proc Natl Acad Sci U S A 1998;95:6460-6464.

103. Pike CJ, Walencewicz AJ, Glabe CG, Cotman CW. In vitro aging of beta-amyloid protein causes peptide aggregation and neurotoxicity. Brain Res 1991;563:311-314.

104. Simmons LK, May PC, Tomaselli KJ, et al. Secondary structure of amyloid beta peptide correlates with neurotoxic activity in vitro. Mol Pharmacol 1994;45:373-379.

105. Soto C, Sigurdsson EM, Morelli L, Kumar RA, Castano EM, Frangione B. Beta-sheet breaker peptides inhibit fibrillogenesis in a rat brain model of amyloidosis: Implications for Alzheimer's therapy. Nat Med 1998;4:822-826.

106. Tsuzuki K, Yamaguchi H, Tateno M, Imai K, Fujii N, Yamauchi T. Transthyretin binds amyloid beta peptides, $\mathrm{A}$ beta $1-42$ and A beta 1-40 to form complex in the autopsied human kidney possible role of transthyretin for abeta sequestration. Neurosci Lett 2000;281: 171-174.

107. Watanabe CM, Wolffram S, Ader P, et al. The in vivo neuromodulatory effects of the herbal medicine Ginkgo biloba. Proc Natl Acad Sci U S A 2001;98:6577-6580.

108. Kaur N, Dhiman M, Perez-Polo JR, Mantha AK. Ginkgolide B revamps neuroprotective role of apurinic/apyrimidinic endonuclease 1 and mitochondrial oxidative phosphorylation against $A \beta 25$ 35 -induced neurotoxicity in human neuroblastoma cells. J Neurosci Res 2015;93(6):938-47.

109. Rhein V, Giese M, Baysang G, et al. Ginkgo biloba extract ameliorates oxidative phosphorylation performance and rescues $A \beta$ induced failure. PLoS One 2010;5(8):e12359.

110. Gella A, Durany N. Oxidative stress in Alzheimer disease. Cell Adhes Migr 2009;3:88-93.

111. Pohanka M. Alzheimer s disease and oxidative stress: a review. Curr Med Chem 2014;21(3):356-64.

112. Lin MT, Beal MF. Mitochondrial dysfunction and oxidative stress in neurodegenerative diseases. Nature 2006;443(7113):787.

113. Perry G, Cash AD, Smith MA. Alzheimer disease and oxidative stress. Biomed Res Int 2002;2(3):120-3.
114. Wei T, Ni Y, Hou J, Chen C, Zhao B, Xin W. Hydrogen peroxideinduced oxidative damage and apoptosis in cerebellar granule cells: Protection by Ginkgo biloba extract. Pharmacol Res 2000;41:427-433.

115. $\mathrm{Wu} \mathrm{Y,} \mathrm{Wu} \mathrm{Z,} \mathrm{Butko} \mathrm{P,} \mathrm{et} \mathrm{al.} \mathrm{Amyloid-beta-induced} \mathrm{pathological}$ behaviors are suppressed by Ginkgo biloba extract EGb 761 and ginkgolides in transgenic Caenorhabditis elegans. J Neurosci 2006;26:13102-13113.

116. Bridi R, Crosetti FP, Steffen VM, Henriques AT. The antioxidant activity of standardized extract of Gingko biloba (EGb 761) in rats. Phytother Res 2001;15:449-451.

117. Colak Ö, Sahin A, Alatas Ö, Inal M, Yasar B, Kiper H. The effect of Ginkgo biloba on the activity of catalase and lipid peroxidation in experimental strangulation ileus. Int J Clin Lab Res 1998;28: 69-71.

118. Sasaki K, Hatta S, Wada K, et al. Effects of extract of Ginkgo biloba leaves and its constituents on carcinogen metabolizing enzyme activities and glutathione levels in mouse liver. Life Sci 2002;70:1657-1667.

119. Rimbach G, Gohil K, Matsugo S, et al. Induction of glutathione synthesis in human keratinocytes by Ginkgo biloba extract (EGb 761). Biofactors 2001;15:39-52

120. Maitra I, Marcocci L, Droy-Lefaix MT, Packer L. Peroxyl radical scavenging activity of Ginkgo biloba extract EGb 761. Biochem Pharmacol 1995;45:1649-1655.

121. Gohil K, Packer L. Global gene expression analysis identifies cell and tissue specific actions of Ginkgo biloba extract, EGb 761. Cell Mol Biol 2002;48:625-631.

122. Sestili P, Guidarelli A, Dacha M, Cantoni O. Quercetin prevents DNA single strand breakage and cytotoxicity caused by tertbutylhydroperoxide: Free radical scavenging versus iron chelating mechanism. Free Radic Biol Med 1998;25:196-200.

123. Scholtyssek H, Damerau W, Wessel R, Schimke I. Antioxidative activity of ginkgolides against superoxide in an aprotic environment. Chem Biol Interact 1997;106:183-190.

124. Pietri S, Maurelli E, Drieu K, Culcasi M. Cardioprotective and anti-oxidant effects of the terpenoid constituents of Ginkgo biloba extract (EGb 761). J Mol Cell Cardiol 1997;29:733-742.

Publisher's Note Springer Nature remains neutral with regard to jurisdictional claims in published maps and institutional affiliations. 